\section{ELENA PONIATOWSKA, AUTOBIOGRAFÍA Y TECNOLOGÍA(S) DEL YO: LA ESCRITURA COMO RESISTENCIA Y FORMA DE VIDA}

\author{
VITTORIA BORSÒ \\ Universidad Heinrich-Heine, Düsseldorf \\ UC-Mexicanistas
}

Las autobiografías ficticias ${ }^{1}$, al negociar entre ficción y realidad, proponen otras opciones de formas de vida. Como en el caso de La «Flor de Lis» ${ }^{2}$ de Elena Poniatowska, Mariana, el personaje a la vez ficcional y autobiográfico, es el eje de una «escritura situada» que busca un posicionamento en el mundo. En ella, la exaltación del yo, típica de la autobiografía, se transforma en el dispositivo de una mirada subversiva hacia la sociedad o la escritura de la historia ${ }^{3}$. De hecho, el yo, que en el discurso realista decimonónico trataba de borrar su presencia, se apodera otra vez del espacio de la escritura con una nueva función. El texto personal transtrueca la topografía del poder propiamente porque en la autobiografía el yo de la escritura no solamente escribe y elabora contextos sociales, sino porque se escribe explorando su posicionalidad frente al mundo (Klahn 2007, 509), cambiando el mapa que está dibujado políticamente bajo los conceptos de nación, identidad y -en el caso de México- mestizaje. Tenemos aquí el gran logro de la escritura del yo de Elena Poniatowska y de otras escritoras mexicanas que se escribieron en textos autobiográficos, ofreciendo con su escritura "otra» posicionalidad con respecto al mundo. Las genealogías de Margo Glantz ${ }^{4}$ fue una de las primeras apariciones.

Si bien debemos a los gender studies la sensibilización de los críticos hacia la natura-

leza performativa del sujeto y de los géneros que se producen por las prácticas culturales (Judith Butler), la concepción dinámica de una sujetividad que se crea en el medio lingüístico-estético no hace diferencia de género. Más bien, obviamente, la emergencia del yo en y por la escritura es un momento clave de la narrativa moderna, cuyo escritor emblemático es Marcel Proust. Sobre la base de éste, Roland Barthes propuso considerar el yo como emergente dentro del espacio textual. El yo se construye en la escritura misma, es un producto del acto de escribir y se moldea y transforma según los caminos de la escritura en los laberintos de la memoria o de los sueños. La escritura es -dice Barthes- una cuestión de ética, de la «moralidad de la forma» 5 .

En el contexto de los estudios sobre nuevas formas de vida, un planteamiento semejante merece hoy en día más atención que la simple discusión de la escritura autobiográfica como género cuya ley sería el "pacto autobiográfico», es decir, la identidad de escritor y narrador $^{6}$ que presupone conceptos esencialistas
1

Norma Klahn propuso este concepto para "narrativas que constituyen un género mixto que para su inspiración toman sucesos y personajes la vez, en su transformación imaginaria» (Norma Klahn, «Cuestionamientos genealóverificables pero insisten, a gicos y genéricos: La 'Flor de Lis' como auto-bio-grafía crítica», en Cien años de lealtad en honor a Luis Leal/One Hundred Years of Loyalty: In Honour of Luis Leal, Sara Poot Herrera, Francisco A. Lomelí y María Herrera-Sobek (eds.), México, University of California, Santa Barbara/
Vittoria Borsò

Catedrática de la Universidad Heinrich-Heine en Düsseldorf. Varios de sus ensayos abordan la oralidad en la literatura mexicana. Esta orientación antropológica se manifiesta en uno de sus últimos ensayos Unidad y pluralidad de la cultura latinoamericana. Géneros, identidades y medios (2006). Otros estudios se han centrado en e análisis del grupo Onda, de México (Literatura mexicana hoy). Singularmente ha prestado atención a la diferencia de acuerdo con la llamada escritura del cuerpo. La obra de Elena Poniatowska la ha trabajado en su libro Fronteras del poder y umbrales corporales. Sobre el poder performativo de lo popular en la literatura y la cultura de masas de México (Rulfo, Monsiváis, Poniatowska).

UC-Mexicanistas/ Universidad Nacional Autónoma de México/ Instituto Tecnológico de Monterrey/ Universidad del Claustro de Sor Juana, 2007, p. 510). Para la definición de autobiografía cf. Norma Klahn, «(Re) Mapeos literarios: desplazamientos autobiográficos de escritoras chicanas», Debate Feminista, 25 (2002), pp. 321-358.

2

Elena Poniatowska, La «Flor de Lis», México, Era, 1988. En lo siguiente, las cifras entre paréntesis en el texto se refieren a esta edición.

En su análisis de variados textos fundadores (de Sarmiento a la autobiografía de Victoria O'Campo) Silvia Molloy enfoca las técnicas transversales con las que las autobiografías hispanoamericanas revelan la memoria represiva de Occidente (Silvia Molloy, La autobiografía en lengua española en el siglo veinte, Lausanne, Sociedad Suiza de Estudios Hispánicos, 1991).

Margo Glantz, Las genealogías, México, Martín Casillas, 1981 (Premio Magda Donato 1982).

5

Roland Barthes, Le degré zéro de l'écriture, Paris, Seuil, 1953, p. 17.

6

Philippe Lejeune, Le pacte autobiographique, Paris, Seuil, 1975.

Elena Poniatowska, autobiografía y tecnología(s) del yo: la escritura como resistencia y forma de vida VITTORIA BORSÒ 
Michel Foucault, Introduction à l'usage des plaisirs, en L'Histoire de la Sexualité, vol. 3, Paris, Gallimard, 1984. Cito de la versión alemana: Miche Foucault. Einleitung zu «Der Gebrauch der Lüste», Postmoderne und Dekonstruktion: Texte französischer Philosophen de Gegenwart, Peter Engelmann (ed.), Stuttgart, Reclam, 1990, pp. $244-274$ y p. 265.

8

Foucault, Einleitung, op. cit., p. 263.

9

Convengo con Norma Klahn acerca del impacto crítico de la autobiografía que, desde la escritura del yo, reconfigura conceptos de nación, identidad y origen en el discurso de la mexicanidad (el mestizaje).

10

Comparten la crítica de las biociencias inaugurada por la biopolítica de Michel Foucault también escritoras y escritores como Judith Butler, Giorgio Agamben $u$ otros a los que nos referimos más adelante.

11

Foucault menciona además de los Hypomnemata, también la correspondencia. Al fungir el destinatario como alter ego, el género epistolar pone en marcha la introspección y el ejercicio del yo frente a lo cotidiano.

12

Foucault se refiere al Peri Euthmias (De Tranquillitate) de Plutarco. La ética no significa una moral entendida como la exigencia de obedecer a un sistema de reglas, sino más bien un arte de vivir, una aspiración a construirse a sí mismo como una obra de arte.

13

Michel Foucault, «La bibliothèque fantastique», Travail de Flaubert, Raymonde Debray Genette et al. (eds.), Paris, Sevil, 1983, pp. 103-122.

Elena Poniatowska, autobiografía y tecnología(s) del yo: la escritura como resistencia y forma de vida VITTORIA BORSÒ de realidad y ficción, así como la existencia de un sujeto definido anterior y exterior al acto de escribir. Son asunciones ya inaceptables no solamente frente a los alcances de la literatura o del cine moderno, sino también a la luz de los recientes estudios neurológicos sobre la memoria o el sueño. Referir el texto de Elena Poniatowska a discursos de género literario sería por lo tanto obliterar la parte más productora de su autobiografía en cuanto espacio de un «training» del yo en busca de su posición frente al mundo. La autobiografía es asimismo una técnica que explora formas de vida y la emergencia de un «ethos» que para Poniatowska se transformó en el signum de toda su obra.

Como es conocido, para la formulación de una teoría performativa de la «sujetividad» Judith Butler se funda en los estudios del «cuidado de sí» y de la «gouvernabilité» efectuados por Michel Foucault en sus últimos escritos, en los que el filósofo francés pasa del análisis del poder al de la ética expresada a través del concepto de 'gobierno' (gouvernement des hommes). Sabemos, por lo tanto, que el sujeto no es soberano en el sentido de una substancia o una instancia jurídica, fundante, sino que es fundado o constituido por las tecnologías del yo, por supuesto, distintas y discontinuas a lo largo de la historia. Dichas prácticas son procesos paradójicos que constituyen el yo subjetivándolo, sujetándolo (assujettissement); son pues formas que Foucault denomina 'ascéticas' porque requieren el ajuste a una manera de ser de acuerdo con las normas sociales y morales.

Conviene recordar las líneas centrales que nos permiten hablar de una «escritura del yo». Michel Foucault entiende por «moral» el código de las técnicas del yo, en concreto un «conjunto de valores y reglas de actuación que se imponen a los individuos y a los grupos por medio de diversos aparatos reguladores: familia, instituciones educativas, iglesia, etc.» ${ }^{7}$. La reflexión moral es por tanto la elaboración y estilización de una actividad en la que los hombres (y las mujeres) «precisamente han de hacer uso de su derecho, de su poder, de su autoridad y de su libertad: las prácticas sexuales» ${ }^{8}$. En tanto que prácticas "pastorales» someten el sujeto a las artes de la existencia («técnicas del yo») domeñando el deseo que amenaza la integridad del yo y estableciendo fronteras entre el mundo interior y el exterior, entre el yo y los otros. Por ello, la individualización está estrechamente vinculada a la diferencia entre los sexos como a la biopolítica o la geopolítica. En su calidad de técnica del yo, el texto autobiográfico vierte una luz crítica hacia la formación del individuo según el Bildungsroman porque enseña que su constitución es el resultado de las «pratiques divisantes», esto es, de las prácticas que establecen fronteras, que dividen al sujeto en dos ámbitos, que diferencian entre lo mismo y lo otro, entre uno mismo y los otros. Sin embargo, además de confinar a las personas en espacios acotados y de someterlas, la técnica del yo posibilita también tácticas de rebelión. El medio del «training del yo», como concientización del poder social y de subversión contra él, es la escritura.

Propiamente en el texto de Poniatowska, la emergencia del yo se manifiesta como toma de conciencia del régimen de la categorización $\mathrm{y}$ de fronteras, y provoca a la vez una resistencia contra él. La autobiografía se transforma por ende en la escena dramática de un yo que aprende a reconocerse frente al deseo de la lucha contra las diferencias sociales o territoriales, y propiamente esto es el hilo conductor de toda la práctica de escritura de Poniatowska. Precisamente en este punto comienza nuestro metódico interés por escrutar en la autobiografía de Poniatowska no solamente en relación con la geopolítica que es, de hecho, uno de los grandes temas ${ }^{9}$, sino también con las biociencias, a las que actualmente se confía la interpretación del ser humano ${ }^{10}$. Veremos así que en la escritura se va perfilando un ethos hacia otras formas de vida, hacia otra antropología.

De hecho, el «training del yo» encuentra en la escritura su instrumento privilegiado: diarios, cartas, ejercicios de la memoria (Hypomnemata), son unas de las técnicas que aseguran la existencia (techne tou biou). La escritura es un ejercicio del yo que se afirma construyendo el lugar de lo otro en el orden de los discursos y una mirada ajena para reconocerse a sí mismo, y es a esta ambivalencia que debemos su función productiva. Frente a los ojos del destinatario, el yo intensifica la vigilancia sobre uno mismo ${ }^{11}$-es una función ethopoiética que transforma la verdad en ethos y carácter ${ }^{12}-$ y a la vez se desdobla en «otro», en una instancia que inscribe también lo excluido, lo asujetado, el cuerpo y el recuerdo (en la autobiografía de Poniatowska es el padre Jacques Teufel).

Foucault mismo reconoce en el medio de la escritura un espacio subrepticio ${ }^{13}$ en el que se expresa lo excluido y se constituye la sujetividad como «otra» posicionalidad. Además, 
toda forma de articulación del sujeto hacia el mundo discurre sobre un medio, el cuerpo, que vincula a las personas a su mundo vital lo que hace la articulación del yo potencialmente móvil y plural. Especialmente en la rememoración del pasado el «training» del yo usa y transforma los logoi sociales, así que la escritura autobiográfica conlleva tanto la consolidación de la identidad social como la dilución de dicha identidad.

En lo siguiente quiero arrojar luces sobre dicha ambivalencia. En ella encontramos la zona indeterminada de la que el sujeto emerge y toma posición. Es la zona de pasaje entre yo y el mundo, el interior y el exterior, o según Gilles Deleuze, 'el interior de un exterior' («le dedans du dehors»). Veremos que, en el caso de La «Flor de Lis», tal indeterminación es la escena de la escritura en el pasaje a México hasta las primeras fases de la socialización en la que el yo experimenta las separaciones y toma conciencia de las fronteras geopolíticas y sociales. Norma Klahn ya apuntó al momento clave de la novela, es decir, la imposibilidad de corresponder al deseo social de territorialización. Es la experiencia extrañante que el yo repite varias veces de sentirse mexicana y no corresponder a los «logoi» de la mexicanidad ${ }^{14}$.

Pues bien, resumiendo, cabe subrayar el proceso de producción y de mediación de emergencias en la forma lingüístico-estética del espacio temporalizado de la escritura ${ }^{15}$, en la que el signo material, en el momento contingente de escribir ${ }^{16}$, difiere del sentido «social». Por ello, la escritura autobiográfica pone en escena no solamente las articulaciones del sujeto, sino también los procesos y los medios con que él emerge. De hecho, al comienzo de La «Flor de Lis», el yo de Mariana se expresa en un medio fluido e indeterminado en el que las imágenes toman forma y son percibidas por el sujeto tras las mediación del cuerpo y según la modalidad de dispositivos ópticos, como la fotografía y el cine. En otras palabras, al comienzo del libro, a través de la focalización interna de la niña, la narradora logra encontrar una articulación que, lejos de cartografiar el mundo, manifiesta la existencia de un sujeto rodeado por él e inmerso en él, cuya percepción se hace por formas de extrema proximidad sensual a las cosas. Por ello, la «primera» mediación al mundo pasa de manera privilegiada por el close up de la fotografía o del cine. A medida que los medios de masa, es decir, los periódicos ${ }^{17}$, o el cine de Hollywood, proporcionan imágenes del orden social del mundo (son los años 40-50 del siglo XX), ocurren más y más citas de una visión orientada hacia la cartografía social del mundo circundante que va desde las imágenes de Hollywood $^{18}$, hasta las estrellas mexicanas en el Club Hípico Francés (Dolores del Río, etc.,

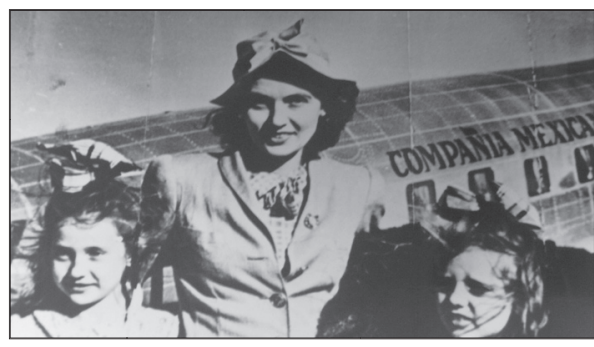
p. 61) hasta las idées reçues católicas y porfiristas de la familia.

Ahora bien, propiamente el dispositivo de la visión, que en Occidente es el trato de unión entre el sujeto y el mundo que lo rodea, hace que el yo de la escritura tope con lo extraño: la fugitividad de Luz, su madre, o el temperamento angustiado del padre, la diversidad del mundo circundante, son mediadores de un desdoblamiento que hace que Mariana, en contra de su hermana Sofía (representante de la sabiduría social), mantenga abierta la búsqueda de su propia destinación, y es solamente más tarde, cuando Mariana forma su capacidad discursiva en el ambivalente diálogo con el padre Jacques Teufel, tomando conciencia de que el ímpetu disidente es desde el comienzo el hilo conductor de su vida.

\section{LA FLUIDEZ DEL MUNDO MATE- RIAL Y LA EMERGENCA DE «OTRA» ANTROPOLOGÍA}

Al comienzo del texto, la focalización interna de la niña, además de ser una convención de la autobiografía que, por ejemplo, Jean Jacques Rousseau adopta en el primer capítulo de Confessions, sirve para mediatizar la emergencia de un espacio que, a los ojos de la niña, todavía no es estructurado por separaciones. La visualidad es el medio con el que la narradora experimenta el conflicto entre el espacio abierto y los límites que lo separan en zonas distintas (interior vs. exterior, yo y los otros, el sujeto y el mundo), y este espacio está marcado en la escena de la primera imagen, genealógica para el desarrollo del texto:

La veo salir de un ropero antiguo: tiene un camisón largo, blanco y sobre la cabeza uno de esos gorros de dormir que aparecen en las ilustraciones de la Biblioteca Rosa de la condesa de Ségur. Al cerrar el batiente, mi madre lo azota contra sí misma y se pellizca la nariz. Ese miedo a la puerta no me abandonará nunca. El batiente estará siempre machucando algo, separando, dejándome afuera (13).
14

La pregunta se formula claramente la primera vez cuando la narradora es consciente de las aporías geopolíticas en la interacción social con los mexicanos (p. 114, cf. Norma Klahn 2007, p. 511), sin embargo está presente desde el primer momento en el que la niña pisa tierra mexicana ( Sofía y yo no sabíamos que mamá era mexicana», p. 32) y se repite en varias formas a lo largo del texto (por ej., pp. 43, 50, 69, 73-75; especialmente en la interacción con Casila, p. 119). Luego va transformándose en un discurso, no carente de exotismo, sobre la naturaleza y la cocina de México.

15

Cf. Vittoria Borsò, «Topologie als literaturwissenschaftliche Methode. Die Schrift des Raums und der Raum der Schrift», Topologie. Zur Raumbeschreibung in den Kultur- und Medienwissenschaften, Stephan Günze (ed.), Bielefeld, transcript, 2007, pp. 279-295, y Vittoria Borsò, "Grenzen, Schwellen und andere Orte», Kulturelle Topographien, Vittoria Borsò und Reinhold Görling (eds), Stuttgart, Metzler, 2004, pp. 13-41.

16

Por el desplazamiento, el concepto de la escritura sustituye a las nociones de estructura. Véase Jacques Derrida, L'écriture ef la différence, Paris, Seuil, 1967.

Véase también Jacques Derrida "Signature événement contexte», Marges de la philosophie. Critique (1972), pp. 365-393

17

El primer indicio son los noticieros sobre los soldados en la Segunda Guerra Mundial (39).

18

Menciona, por ei., a Jane Russe (en The Outlaw) o a Clark Gable $(60,61)$.

Elena Poniatowska, autobiografía y tecnología(s) del yo: la escritura como resistencia y forma de vida VITTORIA BORSÒ 


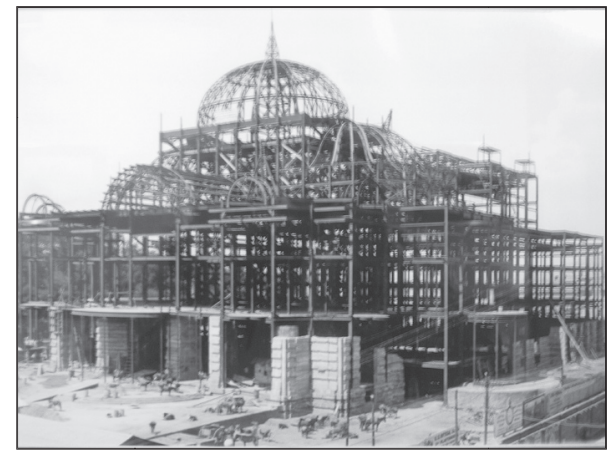

Construcción del Bellas Artes. México D.F.

19

Es obvia mi referencia al principio de la autopoiesis de Humberto Maturana y Francisco Varela, El árbol del conocimiento, Santiago, Editorial Universitaria, 1984.

20

Acerca del uso del primer plano o close up, véase también, Pierre Kast, "Une fonction de constat», Cahiers du cinéma, 7 (1951), pp. 6-16. Bajo el concepto de "efecto de constatación», Pierre Kast concibe, por ejemplo, aquel fenómeno que hace aparecer en la pantalla, repentinamente, una realidad independiente, un efecto a través del cual los objetos se muestran como autónomos respecto al ojo del espectador. También Bonitzer subraya la expresividad del primer plano, que refuerza un "régime physique, affectif, intense» (Pascal Bonitzer, Décadrage. Peinture et cinéma, Paris, $\mathrm{Ed}$. de L'Etoile, 1985, p. 89)

21

Roland Barthes, La chambre claire, Paris, Gallimard, 1980.

Elena Poniatowska, autobiografía y tecnología(s) del yo: la escritura como resistencia y forma de vida VITTORIA BORSOे
La narradora empieza su texto con la referencia al «Bildungsroman» y a los libros como dispositivos que, en el siglo XIX, mediatizan la posición del sujeto frente al mundo -la joven Madame Bovary interpreta el mundo a través de las novelas románticas. Sin embargo, propiamente esa alusión sirve para marcar la diferencia, es decir, el camino de su propia exploración: a) la trascendencia del dispositivo de la vista que, debido a la movilidad del encuadre experimentado con los nuevos medios, la fotografía y el cine, sustituye a la imaginación de los libros; b) la inquietud no es sentimental, sino política. Es, pues, debida al conflicto entre, por un lado, el espacio abierto a los pasajes entre los continentes o entre el interior y el exterior experimentados por la niña, y por el otro, las separaciones que, en el aprendizaje del mundo, adquieren más y más evidencia: separaciones territoriales, diferencias entre mamá y ella, entre criados y amos, entre aristócratas y burgueses, entre ricos y pobres, entre imaginación y realidad. La percepción y el recuerdo que, como sabemos desde la escritura autobiográfica, desde la filosofía del cine (Gilles Deleuze) y, en las últimas décadas, también desde la ciencia de la cognición y la neurología ${ }^{19}$, es una obra de selección y de mediatización vinculada al contexto social, pasa por distintos dispositivos que mediatizan la mirada encuadrando el mundo.

En la fase anterior a la socialización de la niña a través de los plots de las películas de cine o por los discursos sociales en la familia $y$ en el colegio, nos enfrentamos repetidamente a la búsqueda de un posicionamiento mediatizado por el encuadramiento de lo real a través de los nuevos medios, la fotografía o el encuadre cinematográfico. Son imágenes desterritorializadas, mediatizadas por closeup o por el fluir de la visualidad en un espacio todavía indeterminado para el ojo de la niña que, al comienzo de la novela, se enfrenta por primera vez al ambiente aristocrático que la circunda. "La señora duquesa está servida», es de hecho, la primera frase del segundo fragmento del texto, y es aquí que, para la percepción de la niña, diferentes espacios geopolíticos y sociales se superponen: «Un duque más con su gran bonete blanco como el gorro de cocinero en los grabados de la condesa de Ségur»(13).
En la escritura, el dispositivo del ojo de la niña enfoca espacios primordiales, anteriores a las segmentaciones sociales y lo hace en analogía a la cámara cinematográfica, echando una mirada móvil a las pinturas pendientes de las paredes del salón. El movimiento de zoom que acerca los detalles hace que la percepción de las imágenes se emancipe de la lógica sensomotórica, tal como Gilles Deleuze lo describe para el cine experimental y el cine de la memoria. Es así que el ojo de la narradora desterritorializa y abre el campo cerrado de las pinturas en el salón de la abuela, la duquesa:

Para llegar al comedor atravesamos un salón. En un cuadro enorme que ahora sé es de Hundecutter veo un pelícano, un guajolote, varios patos, perdices que cuelgan de un lazo, unas gallinitas de Guinea acebradas. En otro cuadro se asoma un mendigo. Los demás no me impactan, sólo ese mendigo con unos cuantos pelos en la barba y su expresión feroz e implorante bajo la frente vendada. Alarga su mano velluda, me persigue, va a tomarme el cuello (13).

Los primeros planos, como el que la escritora produce en la cara del mendigo, densifican la corporalidad de las imágenes ${ }^{20} \mathrm{y}$ su opacidad. El close-up es a la vez un lugar y un tiempo de passage: la imagen está cargada por los indicios materiales y por la expectativa de algo que, desde el off, puede irrumpir en el campo de la visualidad.

Semejantes imágenes enfrentan al espectador con una visualidad sin centro, una visualidad no enteramente orientada por la organización discursiva o por el simbolismo icónico. Esta escena es tanto genealógica para el yo de La «Flor de Lis» como lo es la escena del pasaje al sueño con la que Marcel Proust empieza la Recherche («Longtemps je me suis couché de bonne heure»). En ambos casos la escritura del yo se posiciona en la zona de pasaje. Sin embargo, el cambio es notable: En el caso de Poniatowska no es la intimidad sino más bien la postura hacia al mundo el germen de la escritura. Desde el comienzo, el sujeto se inscribe pues en las letras de su texto como un yo en busca de «otra» antropología, mediatizada por la cámara obscura de un recuerdo que metamorfosea la pintura del salón de la abuela. Transformado por la técnica del close-up, el mendigo emerge del cuadro como la huella espectral de algo extraño que irrita la vista, inquieta, como el punctum de la fotografía ${ }^{21}$. En la geneaología de esta autobiografía encontramos pues la imagen del 
mendigo, allá, en donde para Roland Barthes o Marguerite Duras está la foto de la madre, una fotografía irrepresentable y con valor genealógico para la escritura del yo.

Como testimonio, en contra, las fotos son simples documentos que legitiman el recuerdo del que sabemos que es frágil: «las fotos lo comprueban», dice la narradora refiriéndose a las tres fotos «tomadas de la mano» por «papá en uno de los fines de semana en que subía a vernos a la montaña» (23) -testigos de ausencias debidas a la guerra, en donde los padres «se quedaron en París en plena zona ocupada» (22-23). Por el recuerdo de las ausencias, pronto también las fotos son mediadoras de lo indeterminado («Yo nunca he visto a un alemán. Tampoco a mis papás», 22), como la instantánea en la que el padre «se ve guapo, de bigote, deslizándose sobre la blancura deslumbrante» (23). Como para el recuerdo, igualmente la percepción visual es mediatizada por un encuadramiento fotográfico ${ }^{22}$, especialmente la percepción de la madre, cuando aparece desde el marco de la puerta a los ojos de Mariana quien, como el joven Marcel, la espera para el beso de las buenas noches: «Apresurada, empuja la puerta como suele hacerlo, con todo su cuerpo, de modo que la puerta la enmarca; cuadro viviente de sí misma« (17) o la mira -así lo dice- «a través de un vidrio impalpable veo a mamá, longilínea, de cara al cielo con toda la lluvia cayéndome encima, dulce mi mamá de agua. Extiendo la mano para secar su rostro empapado. No la alcanzo» (23-24). El lenguaje fluye al dar vida al movimiento, así que, en su geografía personal, el yo ya no distingue entre la proximidad y la lejanía. El primer encuentro de la niña con México es, de hecho, el encuentro con lo abierto. Unos de los primeros recuerdos es el largo fragmento sobre la presencia de los perros en la casa de la abuela mexicana, «la nueva abuela del canotier, [que] tiene ojos amarillos de gato que miran bonito» (33):

Los perros oyen muchas cosas cuando duermen y no es que ladren abiertamente, no: gimen, gruñen, luchan con el ángel, se llenan de demonio, no sé, como cuando hay una perra en brama y la nueva abuela manda a encerrar a todos los que no ha llevado a capar (35).

El entrecruce entre lo animal y lo humano se repite más adelante frente a la amenaza del orden social, por ejemplo, en la imagen de una ruptura en la relación de los padres después de que el papá ha regresado de la guerra: «El uno

frente al otro, inquietos, se miran, veo el borde de sus orejas, sí, tienen las orejas paradas, se acorralan, no sé si van a pelear» (88). Con la semejanza entre lo humano y lo "perruno", el texto pone en juego el esquema binario que fundamenta las reglas de exclusiones e inclusiones. Es un acto de rebelión, opina Giorgo Agamben, un acto que desconecta la máquina biopolítica que distingue entre logos y animal, para entender este último como la forma de vida que carece de humanidad.

El logos occidental cierra, pues, la puerta a lo que estaba abierto, generando aquel sistema jerárquico y excluyente que empieza por la expulsión del animal y llega a la destrucción de razas humanas. Con la visión de la niña, la escritura arroja luz al missing link, a la zona de indiferencia, entre lo humano y lo animal, o lo no humano. Ahora bien, en L'aperto Agamben subraya que la decisión acerca de semejantes separaciones parte de un presupuesto no demostrado; es el presupuesto de la separabilidad de lo humano frente a lo que no lo $\mathrm{es}^{23}$. Posicionarse en esta zona primordial, que no es ni humana ni animal, es decir, anterior a la articulación tópica que desde Aristóteles distingue la vida nutritiva del homo sapiens quiere decir, opina Agamben, oponerse a la obra de exclusión de la biopolítica occidental que va de la producción de homo sacer en la Antigüedad, a la conquista de continentes, la esclavitud, el imperialismo del siglo XIX, la shoah $^{24}$.

En el texto, pues, el aprendizaje del lenguaje como tecnología del yo empieza por la falta de distinciones, por la percepción del continuum entre los seres, y es aquí, que el yo aprende también a contradecir las prácticas con las que la madre, en tanto miembro de la aristocracia, cataloga y excluye a los otros ${ }^{25}$ :

22

Cf. Gilles Deleuze en el segundo comentario de Bergson: «Si le cinéma n'a nullement pour modèle la perception naturelle subjective, c'est parce que la mobilité de ses centres, la variabilité de ses cadrages l'amènent toujours à restaurer des vastes zones acentrées et décadrées》 (Gilles Deleuze, L'image-mouvement, Paris, Sevil, 1983, p. 94. La percepción es, pues, fluyente: "La conscience-caméra [....] $s^{\prime}$ actualisait dans une percep- tion fluente et atteignait ainsi à une détermination matérielle, à une matière-écoulement» (ibid., p. 116).

23

Giorgio Agamben, L'aperto L'vomo e l'animale, Turín, Bollati Boringhieri, 2002, pp. 43-44. La indeterminación de lo abierto es fundamental también para la concepción de 'materia' de Judith Butler. Lejos de definir la esencia de la mujer, la $\chi \omega ́ p \alpha$ platónica es, según la lectura que Butler hace del Timeo de Platón, un 'intervalo', un lugar opaco y sin origen, es decir, anterior a cualquiera formación (Judith Butler, Bodies that Matter, New York, Routledge, 1993). En la crítica del esquema binario que acomuna materia, animal y mujer, encontramos un posicionamiento análogo a la opción crítica (y política) propuesta por Donna Haraway a través de la 'escritura emperrada', entendida como una rama de la teoría feminista en contra de categorías cerradas y excluyentes, como la oposición entre cultura y naturaleza. Cf. Donna J. Haraway, The Compa nion Species Manifesto: Dogs, People and Significant Otherness, Chicago, Prickly Paradigm Press, 2003, p. 8.

24

Signo de lo abierto son las figuraciones de pasajes, de umbrales entre lo animal y lo humano, una articulación híbrida trascendente en los discursos culturales actuales. En L'aperto Agamben parte de la observación de una miniatura contenida en una Biblia hebrea del siglo XIII conservada en la Biblioteca Ambrosiana de Milán, que representa el banquete mesiánico del último día donde los justos se representan en esta miniatura con cabezas de animales. La parusia del último día sería pues la reconciliación entre animales y humanos (Agamben, op. cit., p. 11).

25

Frente a los ojos de la élite, el perro es simple símbolo de inferioridad; la cara de perro es cara de angustia: «Es papá. Frente al teclado, aguardo con cara de perro como papá» (112), dice la narradora recordando su propia flaqueza durante la ejecución de piezas de piano.

Elena Poniatowska, autobiografía y tecnología(s) del yo: la escritura como resistencia y forma de vida VITTORIA BORSÒ 


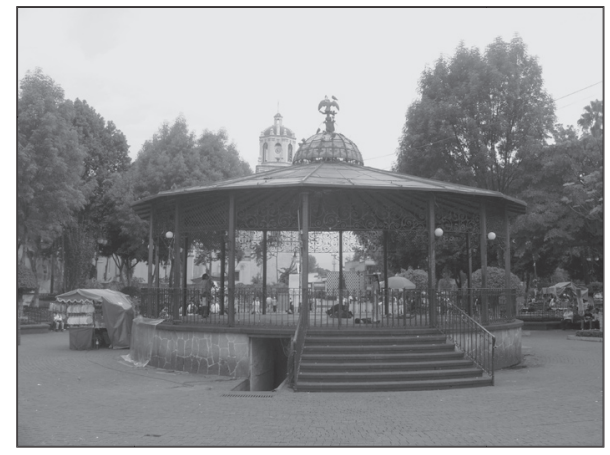

Templete en la plaza de Coyoacán.

26

Me refiero a las disonancias que disconectan la visualidad y el regimen sensomotórico de la imagen.Véase Gilles Deleuze, L'image-temps, Paris, Seuil, 1985.

27

Remito a los estudios que, entre otras cosas, encauzaron una lectura "situada» de Sor Juana: Sara Poot Herrera (ed.), Y diversa de mí misma / entre vuestras plumas ando. Homenaje internacional a Sor Juana Inés de la Cruz, México, El Colegio de México, 1993, y Sara Poot Herrera (ed.), Sor Juana y su Mundo, México, Universidad del Claustro de Sor Juana / Fondo de Cultura Económica, 1995. También a Margo Glantz: Borrones y borradores. Reflexiones sobre el ejercicio de la escritura, México, Porrúa, 1992; "Prólogo». Sor Juana Inés de la Cruz. Obra selecta, Margo Glantz (ed.), Caracas, Ayacucho, 1994, S. XI-XC y Sor Juana Inés de la Cruz: ¿hagiografía o autobiografía?, México, Grijalbo/ UNAM, 1995.

\section{8}

Sara Poot Herrera, «Del tornasol de Lilus Kikus al tornaviaje de 'La Flor de Lis'», en Escribir la infancia: narradoras mexicanas contemporáneas, Nora Pasternac, Ana Rosa Domenella y Luzelena Gutiérrez de Velasco (eds.), México, El Colegio de México, 1996, p. 65.

29

Con el ejemplo de La folie du jour de Maurice Blanchot, Derrida demuestra que un texto no pertenece a ningún género, sino que participa en el repertorio de las demarcaciones y de las contaminaciones del género, de sus repeticiones y archivos (Jacques Derrida, «La loi du genre», Glyph. Textual Studies, 7 (1980), pp. 176-201, 264.

Elena Poniatowska, autobiografía y tecnología(s) del yo: la escritura como resistencia y forma de vida VITTORIA BORSÒ
Amo los magueyes, los miro con detenimiento. Mamá dice que el pulque le da asco porque lo sorben con la boca a través del acocote y luego lo vacían todo ensalivado. Acocote, acocote, acocote, repito fascinada a través de la ventanilla. A mi el aguamiel me endulza el calor; los hombres que lo sacan parecen picaflores, apartan las pencas y hurgan cabeza adentro en el verdor y lo chupan. Lo dejan con su secreto en medio de las piernas verdes al sol. Vengan magueyes, vengan hasta la ventanilla, vengan hacia mí, vengan atentos, leales severos, vengan guardianes, remonten las colinas, atraviesen los barrancos, vengan, soy su general, y ustedes mi ejército, el ejército más portentoso del mundo (37).

Es, desde luego, una percepción cercana a lo que Lévi-Strauss caracteriza como «pensée sauvage», como otra racionalidad, una ciencia de lo concreto y una lógica de lo sensible. La peligrosa armonía en la contigüidad y la atracción entre las palabras produce «faux raccords» ${ }^{26}$, relaciones insensatas con respecto a la lógica discursiva o cronológica y fomenta asimismo la «otra óptica» de la que el yo hará un posicionamiento en el mundo. El intento de conseguir otras formas de geopolítica, formas enredadas, ya se evidencia en el título de la autobiografía: Es el enredo geopolítico entre el México popular y la élite francesa: La 'Flor de Lis' es el nombre del restaurante popular de la Colonia Roma y a la vez el nombre francés de la flor a la que Honoré de Balzac dedicó una de las novelas más sentimentales e idealistas (Les lys dans la vallée, 1834).

\section{LA CONFESIÓN COMO ESCRITU- RA TRANSGRESIVA: JACQUES TEU- FEL}

El discurso confesional, centrado en la batalla del alma, se manifiesta en varios géneros, de la epístola a los diarios, y es una de las tecnologías del testimonio de sí, la verbalización de la propia posición; supone pues un análisis y una introspección de sí mismo. Aunque la confesión representa un tipo de discurso asimétrico, cuya regla principal es la obediencia al superior, propiamente en el acto de escribir la verbalización de todo lo pensado surgen espacios de resistencia transversal y de transgresión. De hecho, existen ejemplos deslumbrantes de la performancia del yo propiamente a partir de la revelación del lado tenebroso y diabólico que la moral cristiana excluye. Santa Teresa demuestra, por ejemplo, que la confesión de los «vicios» y de la debilidad se puede transformar en un acto de autorización del yo, acto que, en el caso de Sor Juana Inés de la Cruz, incluye también «peligrosas» diferencias con respecto a las reglas «pastorales» del $\mathrm{yo}^{27}$. Ahora bien, en el texto de Poniatowska, la ambivalencia de la escritura se desarrolla dentro del discurso mismo del confesor, Jacques Teufel. La narradora trastrueca las reglas de la moral cristiana y transforma el rol del confesor y director de los ejercicios espirituales en el germen de concientización del yo como anhelo de moral y política disidente. La aparición del padre Teufel durante los ejercicios, hace de él un Mefisto tentador y seductor no por la supremacía de un yo soberano, sino por la exposición de un yo a la ética hacia los otros. Además, su discurso se hace eco tanto de la sensualidad mística como de los discursos marxistas de la post-guerra -el nome francés es alusión a la proveniencia de la ideología marxista de aquel momento y del lugar de origen de la narradora, cuyo doppelgänger se encuentra en el sacerdote.

Con Teufel la narradora vierte una luz oblicua a la moral cristiano-burguesa y a su hipocresía. Es una luz que pone de relieve lo que los discursos ocultan: las prácticas de exclusión de la diferencia, diferencia cuya figuración, a partir de la Biblia, ha sido el cuerpo de la mujer. A partir de este momento, el espacio desde el que se inscribe el yo es abiertamente el deseo y el cuerpo de la joven mujer; es desde el espacio de su apertura a la vida y de la incertidumbre de un yo entregado a la pasión, que la escritora, en el encuentro con Teufel, invierte el camino de los ejercicios del yo. Pues, mientras que el sujeto moral, en lucha contra las pasiones «destructoras», se autoriza -por medio de la renuncia (enkrateia) y de la prudencia (sophrosyne)- y se afirma como sujeto virtuoso e independiente, en La «Flor de Lis» el yo se autoriza, en contra, por medio de la pasión inspirada por el otro, a través de los otros. Teufel es el «otro» cuya ambivalente fuerza de seducción consigue invertir y hasta con-fundir las prácticas sociales y, como constata Sara Poot-Herrera, cambia el desarrollo del libro ${ }^{28}$.

\section{ESCRITURA DEL YO Y POLÍTICA DE LA RESISTENCIA}

La mise en scène del género lo identifica con la serie y lo contamina a la vez ${ }^{29}$. Una 
vez más, la ambivalencia de la escritura hace que el sujeto participe en el complejo y variado juego entre las posibles demarcaciones y sus diferencias, entre actos de violencias y de inscripciones subrepticias o disidencias abiertas. Poniatoska disfruta el training del yo y las negociaciones con las diferencias para fortificar a lo largo de la autobiografía un ethos político, con el que sale al fin a la escena pública (Klahn 2007, 520). Lo hace con la experiencia de quien, en los dispositivos «ópticos» y sensuales de la interacción con el mundo material, en la zona de articulación entre yo y el mundo vital que nos rodea, lo que Maurice Merleau-Ponty llamó «la chaire du monde», al que el yo pertenece y que le in-forma, no encontró la identidad, sino la inquietud de la contingencia. El saber que el yo ensaya en su iniciación, concierne también la concientización de sus límites ${ }^{30}$.

De hecho, los últimos dos fragmentos de La «Flor de Lis» son titulados: VITAM AETERNAM y ACCIPE SAL SAPIENTIAE. Contrariamente a la sólida realidad que busca Sofía al «asir la mano del hombre», Mariana es heredera de la «vaguedad y de lo intangible» de la madre. Intangible es la vida por la contingencia y la temporalidad. El fragmento empieza con una imagen de la memoria, en la que tiempos y lugares paralelos se superponen, el vidente y el objeto de la visión se entrecruzan («Atisbo una forma gris que sube la escalera, la veo caminar pequeñísimas distancias de una pieza a otra y me pregunto si ésta que cuenta sus pasos soy yo» (259) y las formas se diluyen. La «confusión martillante, de picapedrero en el fondo del pozo» que le dejó Teufel (260) es una «fusión-con-el mundo»: Los escalones «van ascendiendo en espiral dentro de mi cabeza» dice la narradora que resiste a la sólida esperanza de eternidad. Con el cuerpo de cada sílaba, las palabras contradicen a la violencia de las abstracciones, a la sublimación, para nombrar la finitud de la vida escandiendo con las palabras las huellas de la intensidad del vivir:

Las mismas tripas que tenemos bajo la cintura se enredan en circunvoluciones en nuestra bóveda craneana, divertículos, dicen a la hora de la muerte, pero las de abajo rechinan, chillan como las palabras ${ }^{31}$, las oigo, iiiiiii, uuuuuuuu, son cuerdas vocales mientras que las de arriba sólo trasminan angustia, dejan caer plomo, espadas listas para tasajear el día, las intenciones, la voluntad (260).

La escritura del yo no desemboca en sabiduría, más bien, al final de su iniciación, contradice sus preceptos. "Accipe sal sapientiae» termina con una pregunta: $\dot{i} .$. la tristeza que siento, ¿esa dónde la pongo? ¿Dónde mamá?» Solamente la intensidad del encuentro con el mundo, el estar-en-el-mundo informa el yo acerca de su destino: «Mi país es esta banca de piedra desde la cual miro el mediodía» (261). La escritura del yo es la escena de una resistencia a la doctrina moral o social. Una resistencia cuyo origen no es el yo soberano de las revoluciones, sino la autonomía del mundo material que impresiona al yo, lo inquieta. La escritura, que a través de la analogía con la fotografía y el cine en tanto que dispositivos ópticos del recuerdo y de la percepción había buscado la desterritorialización y desnaturalización de la visión centralizada de los discursos sociales, encuentra su posicionamiento en el abandono de la posición soberana hacia el mundo.

\section{LA ESCRITURA DEL YO COMO GENEALOGÍA: CONVERGENCIAS}

Pues bien, los textos literarios son espacios performativos en los que, además de la constelación de poder, se hallan también las resistencias, los límites del poder. A la constelación del poder las letras oponen resistencias transversales. El poder se hace «por sujetos, no es una máquina metafísica», subraya Michel Foucault con respecto a la relación entre sujeto, espacio y poder ${ }^{32}$. Por muy capaz de inspirar terror que sea un sistema, siempre existen posibilidades de resistencia, de desobediencia y de constitución de grupos de oposición ${ }^{33}$. La resistencia es, por tanto, un componente del poder; la constelación entre el poder y los «objetos del poder» puede invertirse $^{34}$. El poder implica también el polo

30

Encontramos paralelos con la ética de la exterioridad formulada por Emmanuel Lévinas, Totalité et infini (Essay sur l'extériorité), La Haya, M. Nijhoff, 1961. Acerca del concepto de exterioridad, cf. Borsò 2004.

31

Se nota una referencia implícita al poema de Octavio Paz «Las palabras» (Libertad bajo palabra [1935-1953], Enrico Mario Santí (ed.), Madrid, Cátedra, 1988, p.
125). Poniatowska trasloca la articulación del poema de Paz, es decir, la función omnipotente del lenguaje poético. Pues Octavio Paz invoca la violencia de las palabras del poeta (el primer verso de «Las Palabras» dice: «Dales la vuelta, cógelas del rabo [chillen, putas]», p. 125) para desembocar en el lenguaje todopoderoso de la poesía. Además, en el texto poeto lógico que Paz antepone a Libertad bajo palabras, la relación entre el sujeto y el objeto de la mirada, entre el poeta y la mujer, se articula de manera asimétrica: "Invento al amigo que me inventa, mi semejante; y a la mujer, mi contrario: torre que corono de banderas, muralla que escalan mis espumas, ciudad devastada que renace lentamente bajo la dominación de mis ojos». Octavio Paz, "Libertad bajo palabra», Libertad bajo palabra, pp. 71-72. La libertad del poeta crece con su poder pigmaliónico de formar lo otro / la otra, y de someterlos. En su Historia de una mujer que caminó por la vida con zapatos de diseñador (Barcelona, Anagrama, 2005) Margo Glantz trastrueca de manera más marcada el posicionamiento del sujeto en este poema de Octavio Paz. Para un análisis detallado, cf. Vittoria Borsò, «Entre humanos, animales y máquinas: Historia de una mujer de Margo Glantz -la escritura de una antropología que 'nos debe importar'-», en Los otros Méxicos, Juan Bruce-Novoa y Jacobo Sefamí (eds.; en prensa).

32

Michel Foucault, "Le sujet et le pouvoir», Dits et écrits: 1954 1988 (1984), vol. 4, Danie Defert et François Ewald (eds.) Paris, Gallimard, 1994, pp. 222-243. Remito también a mi artículo: Vittoria Borsò, «Fronteras del poder y umbrales corporales. Sobre el poder performativo de lo popular en la literatura y la cultura de masas de México (Rulfo, Monsiváis, Poniatowska)», Iberoamericana. América Latina - España - Portugal 16 (2004), pp. 87-106.

33

«ll n'y a pas des relation de pouvoir sans résistance, sans retournement éventuel» (Foucault Le sujet, op. cit., p. 242)

34

«Une relation de violence agit sur un corps, sur des choses: elle force, elle plie, elle brise, elle détruit: elle referme toutes les possibilités [...] indispensables [...]: que l'autre (celui sur lequel elle [la relación de poder] s'exerce) soit bien reconnu et maintenu jusqu'au bout comme sujet $\mathrm{d}^{\prime}$ action; et que s'ouvre devant la relation de pouvoir, tout un champ de réponses, réactions, effets, inventions possibles. [...] aucun exercice de pouvoir ne peut, sans doute, se passer de l'un ou de l'autre, souvent des deux à la fois» (Foucault 1994, p. 236).

Elena Poniatowska, autobiografía y tecnología(s) del yo: la escritura como resistencia y forma de vida VITTORIA BORSÒ 
Dice Foucault: «Toute extension des rapports de pouvoir pour les soumettre ne peut que conduire aux limites de l'exercice du pouvoir» (Le sujet, op. cit., p. 242).

36

Elena Poniatowska. Luz y luna, las lunitas. Con fotografías de Graciela Iturbide, México, Era 1994.

37

Dice la subscriptio de la fotografía de Tina Modotti por Poniatowska: «EN 1929, EN JUCHITÁN LAS MUJERES LE DEVOLVIERON A TINA MODOTTI EL AMOR A LA VIDA» (Poniatowska, Luz, op.cit., p. 81).

38

Capurro subraya la función performativa e informativa de contexto material negando la interpretación radicalmente constructivista del principio de autopoiesis. Rafael Capurro, Leben im Informationszeitalte, Berlin, Akademie Verlag, 1995.

39

La labor que Poniatowska ha dedicado a la fotografía es comprobada por los varios prólogos y presentaciones de libros de fotografías, entre otras cosas: Manuel Álvarez Bravo, El artista su obra, su tiempo, México, Banamex, 1991; Elena Poniatowska, Mariana Yampolsky y la buganvillia, México, Plaza \& Janés, 2001.

40

Es una cita de la propia voz de Jesusa que comenta la serie de sus cuatro retratos. Los primeros dos, solemnes: "'A MÍ ME LLAMABAN LA REINA XÓCHITL'»; los otros, con una risa más bien carnavalesca: «'AHORA YA NO TENGO EL DIABLO ADENTRO'» (Poniatowska, Luz, op.cit., pp. 52-53).

41

Véase las diesciséis fotografías en el capítulo "Los ojos de Graciela Iturbide» (Poniatowska, Luz, op.cit., pp. 97-112).

42

Le demuestra, entre otros, el siguiente close-up: «Los ojos de Jesusa, en los que se distinguen venitas rojas, están cansados; alrededor de la niña, la pupila se ha hecho terrosa, gris, y el color café muere poco a poco.» (Poniatowska, Luz, op.cit., p. 37).

Elena Poniatowska, autobiografía y tecnología(s) del yo: la escritura como resistencia y forma de vida VITTORIA BORSOे

opuesto: la libertad de los otros que hay que administrar y que detienen una potencia de acción ${ }^{35}$.

En su libro Luz y luna, las lunitas (1994) ${ }^{36}$, Elena Poniatowska pisa el camino hacia «otras» formas de vida, camino que con la autobiografía había vislumbrado en el campo abierto de la infancia, en «otras» formas de mirar al mundo. Cambiando los dispositivos ópticos y por ellos también la posición en el mundo, busca en su obra «otra» antropología y también otros caminos de conocimiento científico-vital. Desde sus crónicas, la escritora halla en el registro popular de la cultura también otros espacios del saber cuyos portadores en este texto, como en toda su obra, son mujeres e indígenas -un paralelo cuyo esquema paternalista y nacionalista invierte la escritora apuntando al saber popular y a sus prácticas «situadas», concretas. De hecho, es desde la posición de un estar-en-el-mundo, desde la fluidez material de las formas, de los recursos de la materia sensible, como la elegancia del cuerpo de la mujer en las fotografías de Tina Modotti ${ }^{37}$, que la escritora se inscribe en las letras, enfrentándose al mundo circundante, dejándose in-formar por él ${ }^{38}$.

Por su corporeidad, los retratos de Jesusa Palancares no son un «hecho» etnográfico para el ojo soberano del escrutador, sino un espacio de relaciones. Poniatowska se interesa por el cuerpo en tanto que constelación cultural de lo potencialmente abierto y transitorio, acercándose a él con la óptica proporcionada por la fotografía ${ }^{39}$. De hecho, en este texto, el juego intermedial, a caballo entre el medio de la fotografía y el de la escritura, es de eminente importancia. De la fotografía ${ }^{40}$, a la escritora le interesa lo que, siguiendo a Roland Barthes, podríamos llamar punctum, un concepto difícil que guarda relación con el sentido expresivo de lo corpóreo, rehusando las connotaciones o clasificaciones sistemáticas del «estudio». Es la parte material de la imagen, que impresiona y punciona, que se demora en la superficie del ornamento, plantea enigmas y perturba el marco perceptivo del observador. Las fotografías de Tina Mo-

43

Roland Barthes, «De la parole à l'écriture», Le grain de la voix: entretiens 19621980, Paris, Gallimard, 1980, pp. 10-13.

44

Poniatowska, Luz, op.cit., p. 38. dotti o de Graciela Iturbide ${ }^{41}$ son testimonio de una semejante fuerza.

Sin embargo, Poniatowska encauza también las letras hacia la inscripción de la materialidad corpórea ${ }^{42}$ tanto de los ornamentos visuales como del "grain de la voix», la singularidad de la voz ${ }^{43}$. Es una cualidad de la voz de Jesusa, que, como juzga la propia Poniatowska en sus comentarios, en la transcripción de las entrevistas grabadas a la novela Hasta no verte Jesús mío la narradora corre el riesgo de borrar domeñando la voz e integrándola en la cultura escrita. Estas reflexiones sobre la posible aculturación etnográfica de Jesusa inquietan a la escritora tanto como la ineludible relación hegemónica entre la persona humilde del pueblo llano, Jesusa Palancares, que se designa a sí misma como «basura», y la aristocrática Poniatowska, hija de una familia de diplomáticos de la nobleza rusa emigrada a México. Y cada miércoles, cuando la escritora visita a Jesusa, toma conciencia de que oscila entre el mundo de los más pobres de México, Distrito Federal y el glamoroso mundo de la élite ${ }^{44}$. Entre ambos espacios urbanos existen fronteras infranqueables, fronteras del poder, y la propia Poniatowska apunta a las insalvables barreras sociales y admite que siempre tuvo la esperanza de que Jesusa no llegase nunca a descubrir su verdadera identidad.

Sin embargo, es por esta inquietud que Poniatowska consigue encontrar caminos para invertir la relación de poder. Pues Jesusa es soberana por su fuerza de vivir. Es la fuerza de un ser que ha conseguido sobrevivir a las convulsiones de la revolución gracias al saber «popular» (como la Generala, como Adelita) ${ }^{45}$, un saber con espiritualidad propia. También a ello hace referencia Poniatowska cuando afirma que Jesusa cree en la reencarnación, que acepta su miseria como castigo por una vida anterior. Es la fuerza que encontramos en la loca Dorotea de Pedro Páramo. Propiamente los retratos de Jesusa que la escritora integra al texto demuestran la intensidad de la anciana mujer, su vinculación al «aquí y ahora», su corporeidad expresiva.

De modo semejante a como ocurre con la campesina de Octubre de Esenstein en los fotogramas II y IV seleccionados por Roland Barthes en su ensayo sobre el sensus obtusus ${ }^{46}$, en el caso de Jesusa también son los espacios del rostro, las cicatrices, las huellas y las arrugas de la vida, los ornamentos de su expresividad, los que puncionan, impresionan e inquietan el régimen del ojo "panóptico» del espectador. Aunque Jesusa se entrega al obje- 
tivo de la cámara, con la expresividad de las arrugas de su cara, mira hacia atrás desafiante, lo que lleva al espectador a una percepción reflexiva, esto es, a meditar sobre sí mismo y su propia relación con la imagen. En este libro de Poniatowska hay una serie de ejemplos de formas de saber vital no ortodoxas: el «otro» saber de los indígenas.

Poniatowska presenta dos tipos de prácticas para aproximarse al saber. El tipo del antropólogo que, incluso en los trabajos de campo, permanece mentalmente en el espacio aséptico de su soberana superioridad cognitiva y clasifica a los otros, no tiene acceso a este saber. Sólo quienes no temen al umbral corporal de la proximidad, quienes se exponen a los espacios del otro, quienes se impregnan del «otro orden» material, sólo ellos invierten las constelaciones del poder. Poniatowska da varios ejemplos de la superioridad del «saber popular». Son, por ejemplo, conocimientos sobre la mejor manera de dar a luz, o sobre prácticas corporales y parodias que desafían la diferencia de sexos, también existente en las culturas llamadas autóctonas. Sólo obtiene el acceso al «otro» quien no pretende abordar ese otro mundo desde la idea de la universalidad de la civilización, ni desde el punto de vista de la soberanía de una dominación biopolítica del cuerpo. En este sentido, la autobiografía de Poniatowska es un texto genealógico para los diversos géneros de la escritura como exploración de "otras» formas de (con) vivir.

\section{BIBLIOGRAFÍA}

Agamben, Giorgio, L'aperto. L'uomo e l'animale, Turín, Bollati Boringhieri, 2002.

Álvarez Bravo, Manuel, El artista, su obra, su tiempo, México, Banamex, 1991.

Barthes, Roland, «De la parole à l'écriture», Le grain de la voix: entretiens 1962-1980, Paris, Gallimard, 1980, pp. 10-13.

- La chambre claire, Paris, Gallimard, 1980.

- Le degré zéro de l'écriture, Paris, Seuil, 1953.

- «Le troisième sens», Cabiers du Cinéma, 222 (1970), pp. 12-19.

Bonitzer, Pascal, Décadrage. Peinture et cinéma, Paris, Ed. de L'Etoile, 1985.

Borsò, Vittoria, «Entre humanos, animales y máquinas: Historia de una mujer de Margo Glantz - la escritura de una antropología que 'nos debe importar'», en
Los otros Méxicos, Juan Bruce-Novoa y Jacobo Sefamí (eds.; en prensa).

- «Fronteras del poder y umbrales corporales. Sobre el poder performativo de lo popular en la literatura y la cultura de masas de México (Rulfo, Monsiváis, Poniatowska)», Iberoamericana. América Latina - España - Portugal 16 (2004), pp. 87-106.

- «Grenzen, Schwellen und andere Orte», Kulturelle Topographien, Vittoria Borsò und Reinhold Görling (eds), Stuttgart, Metzler, 2004, pp. 13-41.

- «Topologie als literaturwissenschaftliche Methode. Die Schrift des Raums und der Raum der Schrift», Topologie. Zur Raumbeschreibung in den Kultur- und Medienwissenschaften, Stephan Günzel (ed.), Bielefeld, transcript, 2007, pp. 279295.

Butler, Judith, Bodies that Matter, New York, Routledge, 1993.

Capurro, Rafael, Leben im Informationszeitalte, Berlin, Akademie Verlag, 1995.

Deleuze, Gilles, L'image-mowvement, Paris, Seuil, 1983.

- L'image-temps, Paris, Seuil, 1985.

Derrida, Jacques, «La loi du genre», Glyph. Textual Studies, 7 (1980), pp. 176-201, 264.

- L'écriture et la différence, Paris, Seuil, 1967.

- «Signature événement contexte», Marges de la philosophie. Critique (1972), pp. 365393.

Foucault, Michel, «La bibliothèque fantastique", Travail de Flaubert, Raymonde Debray-Genette et al. (eds.), Paris, Seuil, 1983, pp. 103-122.

- «Le sujet et le pouvoir», Dits et écrits: 1954-1988 (1984), vol 4, Daniel

Defert et François Ewald (eds.) Paris, Gallimard, 1994, pp. 222-243.

- L'Histoire de la Sexualité, vol. 3, Paris, Gallimard, 1984.

- Postmoderne und Dekonstruktion: Texte französischer Philosophen der Gegenwart, Peter Engelmann (ed.), Stuttgart, Reclam, 1990.

Glantz, Margo, Borrones y borradores. Reflexiones sobre el ejercicio de la escritura, México, Porrúa, 1992.

- Historia de una mujer que caminó por la vida con zapatos de diseñador, Barcelona, Anagrama, 2005.

- Las genealogías, México, Martín Casillas, 1981 [Premio Magda Donato 1982].
Elena Poniatowska, autobiografía y tecnología(s) del yo: la escritura como resistencia y forma de vida VITTORIA BORSÒ 
- Sor Juana Inés de la Cruz: ¿̇hagiografía o autobiografía?, México, Grijalbo/UNAM, 1995.

- (ed.), Sor Juana Inés de la Cruz. Obra selecta, Caracas, Ayacucho, 1994.

Haraway, Donna J., The Companion Species Manifesto: Dogs, People and Significant Otherness, Chicago, Prickly Paradigm Press, 2003.

Kast, Pierre, «Une fonction de constat», Cabiers du Cinéma, 7 (1951), pp. 6-16.

Klahn, Norma, "Cuestionamientos genealógicos y genéricos: La 'Flor de Lis' como auto-biografía crítica», en Cien años de lealtad en honor a Luis Leal/One Hundred Years of Loyalty: In Honour of Luis Leal, Sara Poot Herrera, Francisco A. Lomelí y María Herrera-Sobek (eds.), México, University of California, Santa Barbara/ UC-Mexicanistas/ Universidad Nacional Autónoma de México/Instituto Tecnológico de Monterrey/ Universidad del Claustro de Sor Juana, 2007.

Klahn, Norma, «(Re) Mapeos literarios: desplazamientos autobiográficos de escritoras chicanas», Debate Feminista, 25 (2002), pp. 321-358.

Lejeune, Philippe, Le pacte autobiographie, Paris, Seuil, 1975.

Lévinas, Emmanuel, Totalité et infini (Essay sur l'extériorité), La Haya, M. Nijhoff, 1961.

Maturana, Humberto y Francisco Varela, El árbol del conocimiento, Santiago, Editorial Universitaria, 1984.
Molloy, Silvia, La autobiografía en lengua española en el siglo veinte, Lausanne, Sociedad Suiza de Estudios Hispánicos, 1991.

Paz, Octavio, «Las palabras», en Libertad bajo palabra [1935-1953], Enrico Mario Santí (ed.), Madrid, Cátedra, 1988, p. 125.

- «Libertad bajo palabra», en Libertad bajo palabra, Enrico Mario Santí (ed.), Madrid, Cátedra, 1988, pp. 71-72.

Poniatowska, Elena, La «Flor de Lis», México, Era, 1988.

- Las soldaderas, México, Era, 2000.

- Luz y luna, las lunitas. Con fotografías de Graciela Iturbide, México, Era, 1994.

- Mariana Yampolsky y la buganvillia, México, Plaza \& Janés, 2001.

Poot Herrera, Sara, «Del tornasol de Lilus Kikus al tornaviaje de 'La Flor de Lis'”, en Escribir la infancia: narradoras mexicanas contemporáneas, Nora Pasternac, Ana Rosa Domenella y Luzelena Gutiérrez de Velasco (eds.), México, El Colegio de México, 1996.

- (ed.), Y diversa de mi mismal entre vuestras plumas ando. Homenaje internacional a Sor Juana Inés de la Cruz, México, El Colegio de México, 1993.

- (ed.), Sor Juana y su mundo, México, Universidad del Claustro de Sor Juana/ Fondo de Cultura Económica, 1995.
Elena Poniatowska, autobiografía y tecnología(s) del yo: la escritura como resistencia y forma de vida VITTORIA BORSÒ 